\title{
MARIA PRESTES MAIA: TRAJETÓRIA DE VIDA E LUTAS
}

\author{
MARIA IZILDA SANTOS DE MATOS
}

Pontífica Universidade Católica de São Paulo

RESUMO

A cidade de São Paulo/SP/Brasil tem seu traçado urbano marcado pelo denominado "Plano Avenidas", que foi idealizado e implementado pelo urbanista e prefeito Francisco Prestes Maia. Na ampla bibliografia sobre suas ações são raras as referências a sua esposa, a portuguesa, Maria de Lourdes Costa Cabral Prestes Maia. Esta investigação objetiva dar visibilidade a Maria Prestes Maia, rastreando a trajetória biográfica desta mulher, destacando suas atividades políticas, a atuação na Federação das Mulheres do Brasil, também suas experiências como atriz e professora de teatro, bem como as ações no setor cultural e na assistência social.

Palavras-chave: Maria Prestes Maia. Assistencialismo. Feminismo. Federação das Mulheres do Brasil. Política.

\section{MARIA PRESTES MAIA: LIFE TRAJECTORY AND STRUGGLES}

The plan of the city of São Paulo/SP/Brazil is marked by the so called "Plano Avenidas", which was conceived and implemented by the urbanist and Mayor Francisco Prestes Maia. In the extensive literature about his actions one can barely find references to his wife, the Portuguese Maria de Lourdes Costa Cabral Prestes Maia. This paper aims at tracing the life trajectory of Maria Prestes Maia, a Portuguese immigrant in São Paulo who related her artistic and intellectual activities with local and more global political struggles. Maria's performance in the Brazilian Women Federation, her work experiences as an actress, drama teacher, and relevant actions in the Brazilian cultural and social care sectors, are objective sources of analysis illustrating the importance of this Portuguese artist in Brazilian social history.

Keywords: Maria Prestes Maia. Struggles. Feminism. Brazilian Federation of Women. Politics..

\section{MARIA PRESTES MAIA: TRAJETORIA DE VIDA Y LUTAS}

La ciudad de São Paulo/ SP/ Brasil tiene su trazado urbano marcado por el denominado "Plano Avenidas", que fue idealizado e implementado por el urbanista y alcalde Francisco Prestes Maia. En la extensa bibliografia sobre sus acciones son raras las referencias a su esposa, la portugueas, María de Lourdes Costa Cabral Prestes Maia. Esta in- 
vestigación objetiva dar visibilidad a María Prestes Maia, rastreando la trayectoria biográfica de esta mujer, destacando sus actividades políticas, la actuación en la Federación de las Mujeres de Brasil, también sus experiencias como actriz y profesora de teatro, así como las acciones en el sector cultural y en la cultura asistencia social.

Palabras clave: Maria Prestes Maia. Asistencialismo. El feminismo. Federación de las Mujeres de Brasil. Política.

Estes escritos investigam a trajetória de vida da imigrante portuguesa Maria Prestes Maia, destacando suas atividades políticas, assistencialistas, culturais e a atuação na Federação das Mulheres do Brasil. Entre outras fontes, a pesquisa baseia-se em documentos localizados nos acervos do DEOPS (Departamento Estadual de Ordem Política e Social), depositados no APESP (Arquivo Público do Estado de São Paulo) e em vários depoimentos.

\section{Deslocamentos: questões e inquietações}

Processos migratórios recentes vislumbram o estabelecimento de novas ordens demográficas, não se podendo prever todo o seu desencadeamento e amplitude, mas se constituindo em outros pontos de partida e polos de atração.

As facilidades e agilidades das viagens, somadas às múltiplas possibilidades de comunicação dinamizam os deslocamentos, tornando -os um "acontecimento" perceptível na sociedade atual, mas provocador de tensões, hostilidades, rejeições, conflitos e xenofobia, nas sociedades receptoras. Estas tensões levam ao reconhecimento da importância da temática da migração, ampliando-se os estudos com diferenciadas perspectivas de análise, iluminando interpretações, enriquecendo abordagens e contribuindo para rever estereótipos.

Cabe ressaltar que os deslocamentos carecem de análises que suplantem os condicionamentos demográfico-econômico-sociais e o paradigma mecanicista da miserabilidade, que observem os fluxos além das condições excepcionais de pobreza, fruto das pressões do crescimento da população (modelo malthusiano) ou de mecanismos impessoais do push-pull dos mercados internacionais (CORTI, 2007). Estes processos superaram os limites das necessidades estritamente econômicas, agregando questões políticas (refugiados, perseguidos e expulsos), étnico-raciais, culturais, religiosas, geracionais e de gênero.

Os deslocamentos aparecem como alternativas adotadas por uma gama abrangente de sujeitos históricos, alguns inseridos em fluxo de massa, grupos e familiares, outros em percursos individuais; envolvendo processos de migração engajada, mas, também, voluntária; abarcando diversos extratos sociais, levas e gerações; incluindo agentes inspirados por estratégias e motivações diferenciadas, até mesmo culturais e existenciais. Entre essas múltiplas motivações que levaram à migração, merecem ressalvas a procura da realização de sonhos, da abertura de novas perspectivas, das fugas das pressões cotidianas, da busca do "fazer a América", envolta em variadas representações construídas e vitalizadas neste universo.

Foram vários os mecanismos que viabilizaram este processo, como: a constituição de redes, que incluíam a difusão de informação, chamadas, acolhimento, estabelecimento de relações interpessoais, institucionais, agenciadores, aliciadores, sistema de propaganda, meios de comunicação e a organização do sistema de navegação comercial, que viabilizou o transporte transoceânico em massa. 
A América, em particular o Brasil, que foi polo de atração de imigrantes, chega ao novo milênio em uma outra posição. Como tudo que desempenha a função de revelação dos conflitos e crises por que passam certas áreas, as migrações internacionais contemporâneas criam oportunidades de reavivar as questões em torno do tema e recuperar suas trajetórias históricas.

Nesse sentido, estes escritos pretendem trazer uma contribuição para o estudo da presença portuguesa na cidade de São Paulo. Falar da imigração portuguesa constitui “o resultado histórico de um encontro entre o sonho individual e uma atitude coletiva" (PEREIRA, 1981, p. 9). Estes dizeres sintetizam a importância das histórias de vida para entender o conjunto das experiências individuais e das transformações sociais, bem como a transmissão destas ações para novas gerações através das tradições, questões observadas por possibilidades abertas pela história cultural.

Entre as múltiplas e emergentes indagações que envolvem os deslocamentos, em particular os dos portugueses, mereceria destaque o estabelecimento de circuitos culturais, incluindo a circularidade de artistas de teatro, músicos, pintores, escultores, expoentes das artes plásticas, artesãos e artífices, gráficos, caricaturistas, entre outros, que estiveram ou se fixaram no Brasil, trazendo e deixando suas influências no setor das artes.

Para poder enfrentar tal desafio, torna-se necessário ampliar os focos das pesquisas, subtendendo buscar vestígios de outros tempos. Neste sentido, valorizou-se toda uma diversidade de fontes e referências, tendo como dificuldade mais a fragmentação do que a ausência da documentação, já que as fontes de pesquisa não se resumem ao que está guardado ou arquivado, mas também ao que está silenciado, esquecido e ocultado.
Ao desafio de lidar com esta diversidade de fontes, soma-se o exercício de cruzar, examinar e interpretar contínua e exaustivamente os documentos. Descortinar o passado requer a paciente busca de indícios, sinais e sintomas, a leitura detalhada para esmiuçar o implícito e o oculto, estabelecendo uma relação dialógica, na expectativa de resgatar as múltiplas experiências dos imigrantes portugueses. Para esta investigação, foi privilegiada uma documentação variada, com destaque para os dossiês do DEOPS (Departamento Estadual de Ordem Política e Social), os arquivos de registros de entrevistas de imigrantes do Memorial da Imigração/SP e a imprensa paulista do período.

\section{Cenário: São Paulo a sociedade de acolhimento}

No começo do século XX, São Paulo assumiu seu destino de metrópole, sob o influxo do crescimento industrial, comercial e financeiro. De acordo com o censo de 1920, o número de habitantes atingiu a cifra de 579.033 pessoas, já entre 1920 e 1940, a população novamente duplicou, saltando para 1.326.261 moradores. Em 1934, totalizavam 287.690 estrangeiros (destes 79.465 portugueses), constituindo na cidade um mosaico diversificado de grupos étnicos (Censo Estadual de 1934).

Apesar das dificuldades enfrentadas nos finais da década de 1920 e início dos anos 1930 (crise mundial de 1929 e a queda dos preços do café, Revolução de 1930, perda da hegemonia política da elite paulista e Movimento Constitucionalista de 1932), a indústria continuou se desenvolvendo, atingindo altos índices, no período subsequente (1932-39). Assim, nas décadas de 1930, 1940 e 1950, a cidade consolidou a expansão da industrialização, bem como o crescimento dos setores comerciais e de serviços. As inversões no setor imobiliário ganharam impulso, possibilitando novas edificações, 
tornando São Paulo "a cidade de um edifício por hora" (MORSE, 1970, p. 365), com a redefinição de territórios, como novas áreas comerciais, financeiras e de moradia.

Os planos de intervenção urbana, orquestrados na gestão de Prestes Maia (1938-45), remodelaram a cidade. ${ }^{1}$ Nos dois primeiros anos da sua gestão, centrou suas ações na finalização das obras já iniciadas pelo seu predecessor - Fábio Prado. Seguiu-se um "bota abaixo" até então inusitado: abrindo avenidas, alargando ruas, refazendo ligações viárias. Apesar de já terem aparecido outras propostas, foram priorizadas as soluções já organizadas pelo Plano Avenidas, que estabelecia as características da expansão da cidade, assentadas nos princípios de centralização, expansionismo, verticalização e rodoviarismo. Foram construídos parques, jardins e praças, o Vale do Anhangabaú foi remodelado, além de se dar início a obras que se completariam nas décadas seguintes (Avenida Itororó, hoje 23 de maio, Radial Leste, Avenida Rio Branco, prolongamento da Avenida Pacaembu).

Nos anos de 1950, particularmente durante o governo Juscelino Kubitschek (1955-60), a cidade conviveu com a aceleração ainda maior da industrialização, com a penetração do capital estrangeiro, com a modernização da produção, que possibilitou a ampliação de certos bens de consumo (em particular os automóveis), que tornavam a sociedade mais veloz, também mais conectada pelo rádio, mais visual, com a penetração lenta da TV e marcada por um número crescente de cinemas e teatros.

Em 1961, quando Prestes Maia assumiu novamente o cargo de prefeito, em uma das

1 Francisco Prestes Maia (1896-1965) engenheiro, urbanista e professor da Escola Politécnica de São Paulo, elaborou planos de urbanismo para Campos do Jordão, Santos, Campinas e Recife. Ocupou o cargo de diretor de Obras Públicas de São Paulo e, entre 1938-45, foi prefeito da cidade, nomeado pelo interventor federal no governo paulista - Ademar de Barros. Voltou a assumir o cargo no período de 1961-1965. maiores votações já recebidas por um candidato, São Paulo contava com 3.259.087 habitantes, marcados por profundas desigualdades sociais, vivendo e convivendo, nacionais e imigrantes, migrantes, sobretudo nordestinos envoltos em múltiplas tensões urbanas, experiências fragmentadas e diversificadas.

\section{Um caso de amor à primeira vista}

Enquanto professor da Escola Politécnica, Prestes Maia apresentou um projeto de reforma urbana para São Paulo. Pela primeira vez, a cidade era pensada no todo, em uma concepção de intervenção e de organização espacial, que sintetizava diversas influências, buscando adaptar a estrutura urbana já existente de conformação radiocêntrica, gerando um plano geral baseado em avenidas radiais e perimetrais.

Tratava-se de uma proposta inovadora e foi denominada "Estudos de um Plano de Avenidas para a Cidade de São Paulo", ficando mais conhecido, como "Plano de Avenidas". Em 1930, por estes estudos, Prestes Maia recebeu o Prêmio de Honra, Medalha de Ouro e o Grande Diploma do 4으 Congresso Pan-Americano de Arquitetos, no Rio de Janeiro.

A premiação exigia muitas celebrações. A Capital Federal era marcada por uma estimulante vida noturna, com vários restaurantes, cabarés e teatros, os quais contavam com a presença de grupos de artistas nacionais e europeus. O programa escolhido pelo engenheiro e amigos incluía uma comédia de costume (Chico das Pegas), encenada por uma companhia portuguesa. Nesta ocasião o engenheiro, já com 34 anos e solteiro cobiçado, se encantou pela intérprete e cantora soprano-lírica, a portuguesa Maria de Lourdes.

A atração inicial, pela beleza e desenvoltura da atriz, completou-se com a descoberta de muitos pontos e gostos em comum, a admiração pela literatura francesa, inglesa, alemã, russa, portuguesa, os longos debates sobre as 
grandes obras literárias e filosóficas e as discussões sobre artes plásticas.

Maria de Lourdes ${ }^{2}$ nasceu em Alenquer, em 1901, foi educada num internato, nas redondezas de Paris, onde recebeu instrução refinada, com formação literária e humanística, também aprendendo a tocar piano, cantar e dicção, além das prendas femininas, como bordado, crochê, costura e tricô. Apresentava propensão para as línguas, tornou-se poliglota, sabia ler e escrever com perfeição em francês, inglês, alemão e russo, além de falar com fluência o espanhol e o italiano.

A jovem Maria de Lourdes teve o casamento contratado com um primo, mas as incompatibilidades culminaram no divórcio, com apenas 20 anos. A rejeição familiar levou-a ao isolamento e estimulou o ingresso na carreira teatral, como cantora e atriz. No início de 1930, veio ao Rio de Janeiro acompanhando um grupo teatral, no qual se destacava como cantora soprano-lírica, apresentando-se, na já citada peça Chico das Pega. Nesta ocasião, conheceu o engenheiro Prestes Maia, não retornou mais a Portugal, transferindo-se para São Paulo e passando a residir no luxuoso Hotel Esplanada.

O casal enamorado enfrentou as resistências de D. Carolina, a mãe do engenheiro, fitho único. A família tradicional e católica não aceitava a união, por ser Maria de Lourdes atriz/cantora, presbiteriana e principalmente divorciada em Portugal, situação considerada fora dos padrões morais da época para as muIheres da elite paulistana. Somente cinco anos depois, quando da morte da mãe de Prestes Maia, foi que eles passaram a viver juntos (na

2 Era descendente dos Costa Cabral, bisneta do primeiro Marquês de Tomar, Antônio Bernardo da Costa Cabral (1803-89). Este foi conselheiro de Estado, ministro da Justiça e ministro do Reino e, por duas vezes, durante o governo de Rainha D. Maria II. Seu primeiro mandato na presidência do ministério ficou conhecido como Era Cabralina, neste momento muito conturbado empreendeu o plano de reforma do moderno Estado português. casa da Rua Haiti). Em 1945, nasceu a filha Adriana e o casal se transferiu para a Avenida Angélica. O casamento só ocorreu no leito de morte do engenheiro, em abril de 1965 e de forma nuncupativa. ${ }^{3}$

Foto 01 - Maria de Lourdes

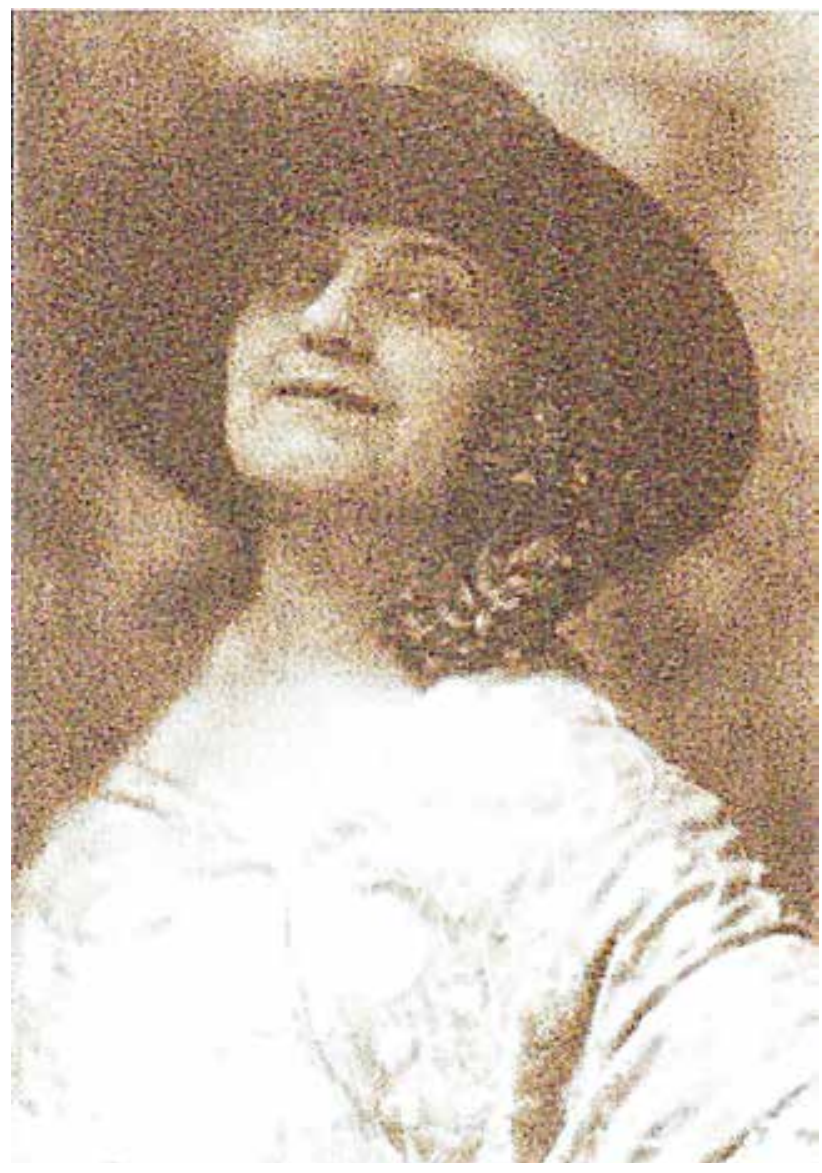

Fonte: FREITAS, Sonia M., 2006, p. 143.

Esta longa relação foi marcada por um convívio complementar, ela extrovertida e impetuosa, ele reservado e conservador. Mulher bonita, elegante, inteligente, comunicativa, bem-criada, apresentava-se com desenvoltura, tornando-se presença obrigatória nos encontros literário-culturais e particularmente no meio teatral.

Nas décadas de 1940 e 1950, acompanhando a prosperidade econômica e as mudanças sociais na cidade, o setor cultural passou por intensas transformações, favorecido pelo mecenato, com destaque para as figuras de Ciccil-

3 Casamento nuncupativo celebrado quando um dos contraentes se acha na iminência de falecer, ou in articulo mortis. 
lo Matarazzo e Assis Chateaubriand. As novidades atingiram as artes plásticas (Museu de Arte de São Paulo MASP - 1947, Bienal de Artes de São Paulo - 1951, Museu de Arte Moderna MAM - 1948), mas especialmente os palcos.

Na capital Paulista implantou-se um sistema cultural denso e diversificado, que irá se expressar ao mesmo tempo no teatro e na vida intelectual, por causa de alterações na estrutura social, decorrente do processo de metropolização por que passava a cidade, e em razão da guerra mundial que gerou a vinda de professores e atores estrangeiros.4 (HAAG, 2010, p. 87)

A cidade tornou-se centro de experimentação no âmbito das artes cênicas, no cinema (Companhia Vera Cruz - 1949) e notadamente no teatro, com a profissionalização deste campo, através da criação da Escola de Arte Dramática - EAD (por Alfredo Mesquita -1948).

Formou-se uma geração de novos interpretes e vários experimentos na área; São Paulo tornou-se um polo modernizador do teatro, ofuscando a cena carioca. O Teatro Brasileiro de Comédia TBC (1948, de Franco Zampari) propunha-se a produzir um teatro requintado, na sua forma (textos, cenários, figurinos, iluminação), para tanto, incorporou cenógrafos, diretores, iluminadores europeus recém-chegados à cidade (PASCHOAL, 1998, p. 28).

Para além do TBC, surgiu o Teatro de Arena (1955), que agregava uma equipe que buscava uma linguagem teatral que fosse mais acessível ao público, se caracterizando como "de vanguarda, nacionalista e popular". Posteriormente, constituíram-se diversos grupos, alguns originários do TBC, como as Companhias Tônia-Celi-Autran e Nydia Lícia-Sérgio Cardoso, outros artistas também fundaram suas companhias: Fernanda Montenegro, Cacilda Becker e Maria Della Costa.

4 A chegada de diretores estrangeiros, como Louis Jouvet, Adolfo Celi, Henriette Morineau, Ziembinsky, Gianni Ratto, contribuiu para a profissionalização do setor. (HAAG, 2010, n. 174, p. 87)
Cativante e eloquente, Maria Portuguesa, como era chamada, foi professora de dicção, oratória, presença cênica, postura e representação, no Teatro Municipal e no Instituto Brasil-Rússia. ${ }^{5}$ Muitos atores de realce foram seus alunos, como Sérgio Cardoso, Madalena Nicol e Paulo Autran, este estreou em cena com a peça $A$ esquina perigosa (Dangerous corner), de J. B. Priestley, traduzida por ela e equipe.

Ela frequentava e influía no meio teatral; tinha amigos como Ziembinsky, Sérgio Cardoso, Nydia Lícia, Bibi e Procópio Ferreira, Paulo Autran, Tônia Carrero, Madalena Nicol, Cacilda Becker, Adolfo Celi, Henriette Morineau, Gianni Ratto, Paulo Gouveia e Tatiana Belinky, entre outros. Apoiou movimentos teatrais emergentes na cidade, como o Teatro Oficina, inaugurado em agosto de 1961, com a encenação de $A$ vida impressa em dólar.

Acho que Zé Celso e eu, embora ainda muito ingênuos naquele tempo, já intuíamos que seria bom ter uma madrinha poderosa que nos ajudasse a resolver entraves burocráticos e exigências.... Quem melhor para nos amadrinhar do que a esposa do próprio Prefeito Prestes Maia? Convidamos Dona Maria Prestes Maia para cortar a fita de inauguração no dia da estréia. Ela aceitou. Dona Maria era uma ex-atriz portuguesa, muito despachada, falante [...]. No dia da estréia depois de pronunciar algumas palavras portuguesas, cortou a fita verde e amarela debaixo de uma salva de palmas. (Depoimento de Renato Borghi)

A nossa madrinha foi Maria Prestes Maia, muIher do prefeito Prestes Maia. Era uma tentativa de burlar a censura que implicara com a presença na peça de palavrões, cenas amorosas,

5 Neste período, difundiram-se na cidade grupos de teatro amador e estudantil, com destaque para o Grupo de Teatro Universitário, Grupo de Artistas Amadores, English Players (da Sociedade Cultural Inglesa), Sociedade de Artistas Amadores, Grupo de Amadores da Faculdade de Ciências Econômicas. Em 1947, os atores amadores Paulo Autran e Madalena Nicol, indicados por Tatiana Belink, procuraram o curso de teatro no Instituto Cultural Brasil-Rússia, oportunidade em que foram alunos de Maria Prestes Maia. (MATTOS, 2002) 
passagens consideradas de pregação marxista [...]. (Depoimento de Etty Fraser)

Maria de Lourdes aceitou o convite, mas não deixou de interferir, fez questão de acompanhar os ensaios, e, como a professora de teatro, apontou dificuldades, tais como: o sotaque carregado e as inflexões duras, a falta de postura cênica, particularmente, as dificuldades com as mãos "ou fumam o tempo inteiro ou enfiam as mãos nos bolsos para esconder a sua falta de repertório", além da ausência de estilo e elegância das atrizes. A análise fazia parte da sua prática, pois escrevia críticas de teatro, música e artes plásticas, em uma coluna denominada "Le Fígaro", usando pseudônimo.

Articuladora cultural tornou-se amiga de Tito Schipa e Arturo Rubinstein, quando estes se apresentaram em São Paulo. Esteve presente em praticamente todos os movimentos culturais da urbe, amiga de Ciccilo Matarazzo e Assis Chateaubriand, apoiou-os em várias iniciativas (MASP, MAM, Bienal).

\section{Salão da D. Maria}

O domicílio do casal Prestes Maia estava sempre repleto de amigos e convidados, tornando famoso o salão de sua residência. D. Maria era considerada excelente anfitriã e capitaneava as atividades, que consistiam em encontros políticos e de negócios, com conversas intermináveis, em um ambiente alegre e descontraído, que envolvia várias atividades: música, poesia, discussões artísticas e políticas. As reuniões eram muito concorridas, verdadeiros saraus, indo até altas horas da madrugada, sempre ao redor de uma mesa farta, com bons vinhos e licores, ao término da refeição.

A casa tornou-se um centro em torno do qual gravitavam amigos, personalidades da vida cultural, artística, empresarial e política, com a presença de jornalistas, escritores, artistas, médicos e cientistas, empresários e po- líticos de diversos partidos, particularmente durante as campanhas políticas do engenheiro. Agregava autoridades como o presidente Juscelino Kubitschek e sua esposa Sara, até notoriedades internacionais como o presidente do Egito, Abdel Gamal Nasser (CAVALCANTI; DELION, 2004).

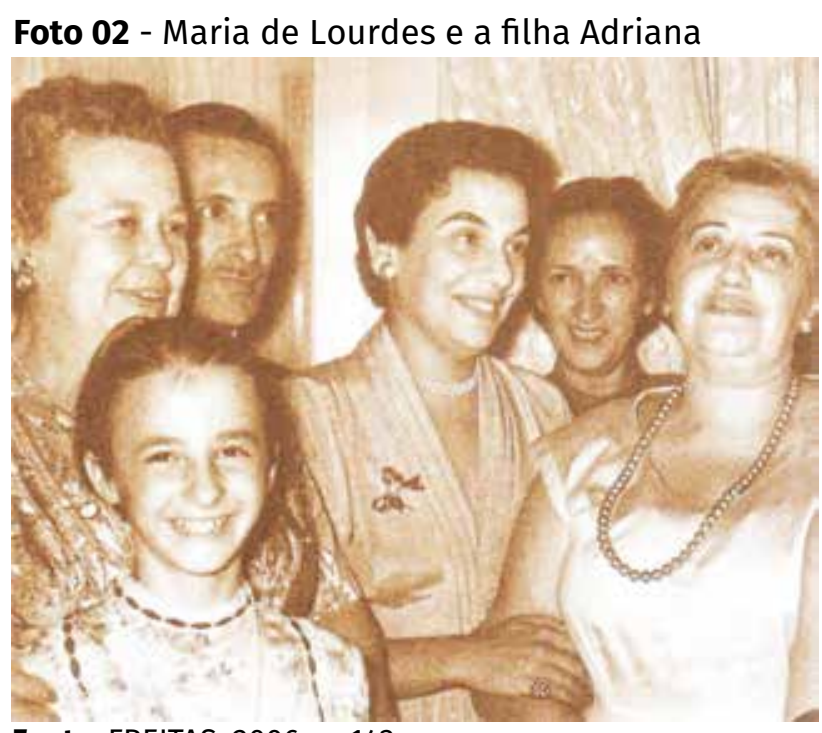

Fonte: FREITAS, 2006, p. 143.

No salão, conviviam jornalistas de realce, como Júlio de Mesquita Filho, de $O$ Estado de $S$. Paulo, Galeão Coutinho, escritor e redator chefe de A Gazeta, Alzira Godói, Francisco Martins, Helena Silveira e Cristina Motta.

Particularmente, contava com a presença de uma variedade de personagens do campo político, como os governadores Jânio da Silva Quadros e Carvalho Pinto, e o ministro San Tiago Dantas. Havia também representantes do legislativo, senador Frota Moreira, os deputados Dagoberto Salles, Herbert Levy, Cunha Bueno, Jamil Haddad, Rogê Ferreira, Wilson Rahal, Israel Dias Novaes e a deputada Ivete Vargas. Advogados e delegados como João Amoroso Neto e Guilherme Pires de Albuquerque. Havia a representação de vários partidos políticos, alguns que deram apoio político ao engenheiro em momentos variados de sua trajetória, como: União Democrática Nacional (UDN), Partido Trabalhista Brasileiro 
(PTB), Partido Democrata Cristão (PDC), Partido de Representação Popular (PRP), Partido Social Democrático (PSD), Partido Republicano (PR), e outros, pelos quais D. Maria tinha uma simpatia particular, como o Partido Socialista Brasileiro (PSB) e Partido Comunista Brasileiro (PCB).

Luiz Carlos Prestes, o Cavaleiro da Esperança, era amigo de Maria de Lourdes, por várias vezes esteve hospedado em sua casa, mesmo nos períodos de clandestinidade (Depoimento de Adriana Prestes Maia Fernandes).

Sua casa foi palco de amplas articulações políticas, não só eleitorais, o movimento conhecido como "Frente Parlamentar Nacionalista", com plataforma anti-imperialista, germinou no seu salão.

A bandeira da luta interna era a luta antiimperialista, a luta pela reforma agrária e a luta pela industrialização. São as três bandeiras nacionalistas e que eram também do partidão na época. É por isso que o movimento nacionalista foi um movimento nacionalista brasileiro de esquerda, não ideológico, não era marxista. Então não era um movimento xenófobo, nem era um movimento de cunho marxista. Agora, os da linha comunista militavam no movimento em razão de seu caráter antiimperialista. (Depoimento de Adriana Prestes Maia Fernandes)

O salão era frequentado, também, por personalidades do mundo cientifico, como o Dr. José Rosemberg, famoso tisiologista e com quem D. Maria abraçou a luta antituberculose, e o físico Mário Schenberg.

Além do mais, ali conviviam artistas, literatos e intelectuais, poetas e escritores, como Guilherme de Almeida, Menotti Del Picchia, Ian de Almeida Prado, Antônio Soares Amora, Augusto de Souza, Fidelino Figueiredo; as pianistas Antonieta Rudge e Helena Rudge, os maestros Edoardo Guarniere e Armando Bellardi; artistas plásticos como os pintores Waldemar da Costa, Rebolo, Di Cavalcanti e Germana de Angelis, os escultores Galileu Ememdábile, Ri- cardo Picchia e Victor Brecheret, que fez várias obras para a cidade durante a gestão de Prestes Maia. Não faltava também a turma do teatro, para a qual D. Maria dedicava um carinho e atenção especial.

Maria de Lourdes era excelente dona de casa, perfeccionista e muito exigente. Dedicada ao marido, cuidava sempre da sua aparência e com capricho da casa. Adorava cozinhar e era reconhecida por seus méritos, dominava todas as etiquetas à mesa e os segredos das boas receitas (que guardava os segredos a sete chaves, escrevia suas receitas em vários idiomas para que não fossem apreendidas), particularmente as de tradição portuguesa.

Ela fazia uma açorda, prato português, que era uma delícia. Pratos de bacalhau, suflês, carnes, coelhos, patos, pernis e doces portugueses, arroz-doce cremoso, bolos. Ela tinha o dom para fazer pratos, tanto salgados quanto doces, todos com perfeição. 0 arroz-doce era cremoso, feito com vários litros de leite, várias gemas, cravos, canela, era cremoso, com raspas de limão e era devorado em questão de minutos pelos convidados. Era a sobremesa favorita do dia de reis, e outras festas. Nesse dia chamava os amigos, servia uma saborosa bacalhoada, com vinhos portugueses, e o célebre arroz-doce.

Ela era uma pessoa muito festeira, adorava ter a casa repleta de amigos, comendo e bebendo bons vinhos e licores, ao término da refeição. Trata-se de um costume bem lusitano, que herdei e procuro passar aos meus filhos. Outro costume dela era o cálice de vinho do Porto, sempre servido às visitas. (Depoimento de Adriana Prestes Maia Fernandes)

Maria de Lourdes era determinada e sedutora, tinha muitas habilidades no trato com as pessoas, e não media esforços para conseguir seus desígnios. Ela gostava da política e ajudou ativamente o marido nas campanhas, pois ele era mais introvertido e contava com a ação envolvente da esposa, com sua eloquência, convencimento e articulações partidárias. 
“A primeira operária" de São Paulo

Maria Prestes Maia não gostava de ser chamada de primeira dama, nomeando-se "primeira operária" de São Paulo. Preocupada e vinculada às questões sociais e assistenciais, sua atuação nestas áreas não se limitou aos períodos de gestão de Prestes Maia. A criação, administração e apoio a entidades filantrópicas e assistenciais estiveram presentes na sua trajetória, assim como na de outras primeiras damas (SIMILI, 2008), transferindo para a esfera pública as funções femininas de "cuidadora" (junto a crianças, velhos e doentes).

Empenhada nestas ações, ela buscou agregar apoio e adesão às suas causas, particularmente das mulheres da elite, mas também do setor empresarial. Fazia uso hábil da máquina administrativa em nome da filantropia, tendo como marco as mesmas:

Concepções e práticas que orientaram a atuação das mulheres na política dos anos $30 \mathrm{e}$ 40. As questões sociais e assistenciais relacionadas ao feminino, à maternidade, à infância estiveram na agenda da atuação das mulheres em vários campos da política, criando uma história das mulheres na política social e assistencial. Integram essa história, Carlota Pereira de Queiroz e Bertha Lutz, as quais como deputadas, participaram da criação de políticas públicas direcionadas à maternidade e à infância; Pérola Byinton que, em São Paulo, criou a Cruzada Pró-Infância, por meio da qual foram desenvolvidos vários programas e serviços de proteção à infância e à maternidade e de Darcy Vargas, que por intermédio da organização de associações e entidades assistenciais traz as marcas das representações presentes no universo feminino da época de que a mulher tinha um papel a cumprir na sociedade, que era o de ser esposa e mãe e que suas causas deviam ser em defesa de problemáticas relacionadas ao feminino e que a ele diziam respeito, tais como a maternidade e a infância. (SIMILI, 2008, p. 58)
Além das ações contínuas nas associações filantrópicas, com apoio à maternidade e à infância carente, à velhice e aos doentes (particularmente nas campanhas de combate à tuberculose), ela realizou:

Natais memoráveis para as crianças das creches, parques e escolas municipais. Na ocasião convocava as amigas e a família para ajudar. 0 ponto de encontro era o Estádio do Pacaembu, lotado de brinquedos, verdadeiro quartelgeneral. (Depoimento de Adriana Prestes Maia Fernandes)

Maria de Lourdes teve atuações estratégicas na política cultural da cidade, cabendo lembrar seu empenho na criação da Escola Municipal de Bailado, em 1940. Esta tinha por objetivo a formação de bailarinos, como o apoio às montagens das temporadas líricas, nacionais e internacionais, e a formação de quadro para o corpo de baile do Teatro Municipal.

A Escola de Bailado era influenciada pela cultura europeia. Inicialmente, esteve instalada nos altos do Teatro Municipal, e, devido ao grande sucesso da iniciativa, houve a necessidade de ser transferida para um espaço maior, embaixo do Viaduto do Chá, sendo capitaneada pela consagrada bailarina russa Maria Olenewa, ${ }^{6}$ convidada por D. Maria, em 1942, para assumir a direção da escola.

Nas duas gestões do engenheiro na prefeitura, ela se encarregou das temporadas líricas, influenciando na programação e na definição dos corpos estáveis do Teatro Municipal:

Segundo é voz corrente nos meios artísticos desta capital, uma portuguesa, amantes do senhor prefeito Prestes Maia, é quem 'manda' no Teatro Municipal, na Orquestra Sinfônica e instituições outras pertencentes ao Departamen-

6 Maria Olenewa (1896-1965) nasceu em Moscou, foi primeira bailarina da Companhia Anna Pavlova e atuou na França e em outros países da Europa. No Brasil, participou da fundação a Escola Oficial de Dança (1927) e do corpo de Baile do Teatro Municipal do Rio de Janeiro (1936). Em 1942, assumiu a Escola de Bailado Municipal de São Paulo, posteriormente montou sua própria Escola de balé. (PAVLOVA, 2001) 
to de Divulgação Artística da prefeitura. Disse algures, que parece obter qualquer coisa nesse setor da administração municipal é preciso, primeiramente, conquistar com atenções e presentes, essa senhora [...]. ${ }^{7}$

Outras ações de Maria Prestes Maia envolvendo o Teatro Municipal também foram denunciadas pelo DEOPS, cabendo destacar suas atuações junto ao Sindicato dos Músicos e a Ordem dos Músicos de São Paulo, através do apoio "Aos senhores Eduardo de Guarnieri e Armando Bellardi, a fim de que os mesmos, em companhia de conhecido comunista Constantino Milano Neto, controlassem a Ordem dos Músicos de São Paulo".

Seu envolvimento apareceu no inquérito aberto em junho, poucos meses depois do golpe militar de março de 1964, centrado na questão da contratação para espetáculos musicais de artistas russos, também na presença na plateia de personalidade da esquerda brasileira, como Luis Carlos Prestes e na difusão de "ideias comunistas" entre os componentes da Orquestra.

Neste sentido, foram realizadas investigações no Teatro Municipal de São Paulo, priorizando o depoimento do maestro Armando Bellardi," que assumiu a direção das programações da casa com a licença do maestro Edoardo de Guarnieri.

7 Dossiê DEOPS/AESP, n. 52-Z-0-14224, doc. 20k1102.

8 Em 1964, após o golpe militar de março, Constantino Milano Neto, que dirigia a Ordem dos Músicos de São Paulo e o Sindicato dos Músicos, foi acusado de pertencer ao Partido Comunista e acabou destituído da Ordem, com a implantação de uma Junta interventiva, abril/64. Dossiê DEOPS/AESP, n. 52-Z-0-14224. Relatório referente à "Ordem dos músicos do Brasil", datado de $12 / 5 / 64,30-C-1-16111$ e 30-C-1-16470.

9 Em 1939, durante a primeira gestão de Prestes Maia na prefeitura de São Paulo, Armando Bellardi, considerado "apadrinhado" de D. Maria de Lourdes, tornouse diretor artístico do Teatro Municipal de São Paulo, onde criou o Coral Lírico, concretizando, posteriormente, a oficialização da Orquestra Sinfônica de São Paulo (1949), também chamada de Orquestra do Teatro Municipal de São Paulo. Consolidando as relações de amizade, em 1945, Bellardi batizou Adriana, filha do casal Prestes Maia. (Depoimento Adriana Prestes Maia Fernandes)
Bellardi declarou que era o responsável pelas programações do Teatro, e que por ocasião do concerto do maestro José Siqueira, estiveram presentes e ocuparam lugares de honra na platéia, Luis Carlos Prestes, Maria de Lourdes Prestes Maia e Edoardo de Guarnieri etc.

Inquirido por nós sobre a influência que ressaltaria nos músicos da Orquestra Sinfônica Municipal, em relação à disciplina a simpatia ao esquerdismo, maestro Bellardi esquivou-se de responder... Todavia as informações que obtivemos são de que o entrosamento entre este senhor e a senhora Maria Prestes Maia era/é perfeito, nada fazendo o maestro, sem consultar dona Maria, o que evidencia ser ele partidário do esquerdismo de modo "velado", tanto é verdade que, após ter programado, autorizado um conserto com artistas Russos (membros oficiais da música comunista) no Teatro Municipal, manda em seguida, para 'salvar as aparências' programar um conserto com as grandes expressões brasileiras: Guiomar Bereis, Sonia Lima, Antonieta Raigo [...] 5 de Junho de 1964.10

Apesar do tom de denúncia, característico da documentação da polícia política, percebem-se as ações e influências de D. Maria, na esfera cultural da municipalidade de São Paulo, durante as gestões Prestes Maia e também em outros momentos. Além disso, sua inserção no métier artístico e as relações com a intelectualidade e artistas de esquerda.

\section{A luta feminista}

No final da década de 1940 (1949), constituiu-se a Federação das Mulheres do Brasil (FMB), que englobava militantes feministas de várias tendências de esquerda, com forte influência do Partido Comunista Brasileiro (PCB). A entidade, que mantinha articulações internacionais, tinha como principais bandeiras a luta pelos direitos da mulher, a paz mundial, a proteção à infância e as ações contra a carestia. Buscava agir junto aos sindicatos, através da instalação

10 Dossiê DEOPS/AESP, n. 52-Z-0-14224. Relatório referente ao Teatro Municipal de São Paulo, 50H942027/ Doc. 360. 
de departamentos femininos e da participação em movimentos como a "Greve dos 300 mil" (março de 1953). Particularmente, atuou na luta contra a carestia, propôs o "Plano Nacional contra a Carestia" e coordenou as ações para a realização da grande "Passeata da Panela Vazia" (março/1953, reunindo mais de 60 mil pessoas), tendo como resposta do governo o estabelecimento da Superintendência Nacional do Abastecimento, que visava agir neste setor.

Maria Prestes Maia atuou ativamente na Federação das Mulheres do Brasil, particularmente no setor São Paulo, em vários momentos e como membro da diretoria no Departamento de Assistência Social (1958). Em 1961, foi convidada para assumir a presidência nacional da entidade, mas declinou devido à eleição de Prestes Maia para a prefeitura, mantendo, contudo, sua colaboração financeira à instituição.11

Mesmo frente às resistências do marido, e como representante da FMB, foi a congressos na Europa, visitou a URSS, Checoslováquia, Polônia, Hungria, lugoslávia, Bulgária, sempre se destacando por sua capacidade de oratória e de cativar as pessoas (Depoimento de Adriana Prestes Maia Fernandes).

A polícia política paulista acompanhou as ações de Maria Prestes Maia na FMB, arrolando vários momentos da sua participação, em julho de 1951, quando ela atuou no Primeiro Congresso da Federação de Mulheres do Brasil, em São Paulo. Já em 1957, estava presente na cerimônia de reabertura da FMB, na nova sede localizada na Rua da Liberdade, 120, 1. Andar (1957). Em maio de 1958, ela organizou, no Teatro Municipal de São Paulo, a Conferência Nacional Preparatória para o quarto Congresso da Federação Democrática Internacional de Mulheres.

No ano 1958, Maria Prestes Maia compôs a delegação paulista da FBM no IV Congresso

11 Dossiê DEOPS/AESP, n. 52-Z-0-14224, docs 50-J-104-826 e $50-C-1-14621$. da Federação Democrática Internacional de Mulheres, realizado em Viena. Após o evento, em convite oficial à comitiva brasileira, visitou vários países do leste europeu e a URSS. No retorno, participou da Conferência realizada na Biblioteca Municipal de São Paulo, em 28/8/1958.

Maria de Lourdes Prestes Maia, uma das comunistas que fez parte da mesa, após fazer o histórico da Federação Internacional de Mulheres Democráticas, apresentou amplo relatório, do 4 congresso Internacional de Mulheres, realizado em Viena referindo-se entusiasmada aos resultados alcançados, descrevendo os trabalhos ali realizados.

Maria Prestes Maia disse que estiveram em visita á URSS a convite das mulheres soviéticas, tendo visitado diversas cidades do país socialista, assim como tomaram contato com organizações de assistência a infância, a maternidade e também sobre a vida das mulheres na URSS. ${ }^{12}$

Já em dia 14/11/1959, D. Maria foi a principal oradora na reunião preparatória para o de "Encontro de Mulheres Latino-Americanas", realizado em Santiago do Chile.

Ela permaneceu fiel à FMB até o encerramento da instituição, continuando a luta e envolvendo-se diretamente na campanha de desarmamento infantil, estando sempre atuante nas ações democráticas e simpática às causas de esquerda.

Segundo relatório reservado de 13/4/61, a líder comunista Eliza Branco Batista, falando do 'Encontro das Mulheres Latino-Americanas', que seria realizado no Rio de Janeiro, de 21 à 23/4/61, por determinação da Federação Internacional de Mulheres, para tratar de suas reivindicações, inclusive da paz e da defesa da revolução cubana, disse que uma delegada daquela Federação estivera no Brasil para preparar o referido 'encontro'. Adiantou também, que a aludida Federação achava muito fraco o movimento das mulheres na América Latina e que a Sra. Maria de Lourdes Prestes Maia, mem-

12 Dossiê DEOPS/AESP, n. 52-Z-0-14224. 
bro do Conselho da Federação das Mulheres do Estado de São Paulo, fora convidada para assumir a presidência daquele organismo, porém declinara do convite, em virtude de outras tarefas que tinha. Eliza Branco Batista esclareceu, inda que, a esposa do Sr. Prefeito Prestes Maia auxiliava pessoalmente, digo financeiramente, o Partido Comunista do Brasil e a Federação das Mulheres do Estado de São Paulo.13

\section{A Luta Política}

As décadas de 1950 e 1960 se caracterizaram pela expansão e a criação de novas expectativas sociais, econômicas e políticas. À política econômica desenvolvimentista, emergente com o governo de Juscelino Kubitschek (195661), somaram-se novas manifestações culturais (música, cinema, teatro, arquitetura), intensas mobilizações da sociedade civil e das instituições políticas. Neste processo, destacou-se a emergência de movimentos sociais e sindicais (nas cidades e no campo), criando um quadro crescente de ampliação das reivindicações democráticas, expansão das articulações nacionalistas, com novas proposições sintetizadas nas Reformas de Base. As tensões internas crescentes, em uma conjuntura internacional intervencionista na América Latina, levaram a articulações políticas que culminaram no golpe militar de 1964.

Neste contexto, Prestes Maia manteve-se atuante no campo político. Depois da gestão na prefeitura de São Paulo (1938-45), foi candidato ao governo paulista, pela União Democrática Nacional (UDN) em 1950; novamente, em 1954, voltou a concorrer à administração do Estado, em uma articulação partidária composta pela UDN, com o apoio de parte do PTB e dos partidos Social Democrático (PSD), Republicano (PR), Democrata Cristão (PDC) e de Representação Popular (PRP); já em 1957, disputou a prefeitura da capital com o apoio da UDN e de frações do PTB. Depois destas três derro-

13 Dossiê DEOPS/AESP, n. 52-Z-0-14224 e 50-J-104-826. tas, em 1961, saiu vitorioso no pleito à prefeitura paulistana, obtendo uma votação maciça, ocupou este cargo até sua morte em 1965. Em todos estes momentos, D. Maria participou ativamente das articulações políticas para o encaminhamento da candidatura do engenheiro, pois era determinada, envolvente, eloquente, com habilidades no convencimento e não media esforços para conseguir seus desígnios.

Contudo, suas ações políticas iam muito além destas intermediações, incluindo opções e preferências pessoais. Possivelmente, nunca chegou a se filiar a qualquer partido, mas cultivava simpatias pelos de esquerda.

No vasto dossiê localizado nos Arquivos do DEOPS, Maria Prestes Maia teve seus passos registrados pela polícia-política (1945 a 1969), foi identificada participando de atividades, comícios e atos públicos junto às lideranças do Partido Comunista e do Partido Socialista, engajando-se na luta nacionalista e pela democracia, no Brasil e em Portugal. As referências a sua pessoa foram mais frequentes, no período de 1957 a 1964, podendo-se conjecturar se isso se deve ao fato destes anos coincidirem com a gestão de Prestes Maia na prefeitura (1961-65), ou talvez a uma maior ação política de D. Maria, ou ainda à própria conjuntura de grandes tensões e movimentos político-sociais, levando a uma maior articulação do equipamento de investigação policial, mas talvez todos estes fatores devam ser observados conjuntamente.

Nos documentos do DEOPS encontram-se referências de reuniões do Partido Comunista realizadas na residência de D. Maria. ${ }^{14}$ Luís Carlos Prestes frequentou e se hospedou várias vezes em sua casa, e o nome dela foi encontrado nas famosas "cadernetas de Prestes".15

14 Dossiê DEOPS/AESP, n. 52-Z-0-14224, doc. 20K110B:05/11/1945.

15 Após o Golpe de 1964, com o Al-1, Luis Carlos Prestes teve seus direitos políticos revogados, perseguido pela polícia, conseguiu fugir, mas na sua casa foi localizada uma série de cadernetas, que forneceram dados e nomes para a base de inquéritos e processos. 
Em janeiro de 1958, quando o PCB já estava na ilegalidade, ${ }^{16}$ ela foi citada pelo órgão do partido o jornal "Notícias de Hoje":

[...] como uma das pessoas presentes a homenagem prestada a Luiz Carlos Prestes, pela passagem do seu 60 aniversário, homenagem essa efetuada no Teatro de São Paulo na noite do dia anterior e intitulada 'Noite de arte e cultura brasileiras'.17

Dias depois (23/01/58), no mesmo jornal, ela subscreveu a nota de:

'Homenagem da mulher paulista à Anita Locadia Prestes', um pedido de adesão de mulher de São Paulo, o baile de homenagem a ser oferecido, no ginásio do Pacaembu à filha do líder comunista Luiz Carlos Prestes. ${ }^{18}$

O seu contato com o líder comunista mantinha-se e, em 1959, ela esteve presente na:

[...] conferência proferida no dia 12/06/59, por Luis Carlos Prestes, na Faculdade de Direito da USP, diz a mesma contou com uma maioria de comunistas militantes, e que, entre as 600 ou mais pessoas presentes, foram notadas: Miguel Jorge Nicolau, Maria Prestes Maia, Mário Schenberg, Milton Marcontes, João Lousada e outros, que aplaudiam entusiasticamente o líder vermelho. ${ }^{19}$

Não se pode confirmar a sua filiação ao PCB, todavia, ainda segundo relatório de 25/3/1963 (período em que seu marido ocupava a prefeitura da cidade), Maria de Lourdes foi coroada uma das "rainhas", na festa em comemoração ao $41^{\circ}$ Aniversário do Partido Comunista Brasileiro, realizada no Ginásio Municipal do $\mathrm{Pa}$ caembu. ${ }^{20}$

"Consta o nome da epigrafada nos apontamentos de Luis Carlos Prestes" (caderneta n. 13). Dossiê DEOPS/ AESP, n. 52-Z-0-14224, doc 50-Z-9-3828/3832.

16 O PCB foi criado em 1922, após a Intentona Comunista de 1935, e, com a prisão de seus membros, tornou-se ilegal. Em 1945, retornou, obtendo registro partidário, elegendo representantes no parlamento; já em 1947 teve seu registro cassado e os mandatos de seus parlamentares extintos no ano seguinte.

17 Dossiê DEOPS/AESP, n. 52-Z-0-14224.

18 Dossiê DEOPS/AESP, n. 52-Z-0-14224.

19 Dossiê DEOPS/AESP, n. 52-Z-0-14224.

20 Dossiê DEOPS/AESP, n. 52-Z-0-14224, docs. 30-C-15408
Em um contexto marcado pela Guerra Fria e com várias repercussões no Brasil, Maria Prestes Maia foi membro atuante em associações representativas dos países comunistas, como a União Cultural Brasil-URSS, na qual ela foi professora de teatro, participou das atividades culturais e integrou o Conselho Consultivo, aparecendo na relação de envolvidos no inquérito do DEOPS sobre a associação. ${ }^{21}$

Integrou também a Sociedade Cultural Sino-Brasileira,

Informa-nos comunicado reservado que o dia 24/10/60, na sede social da 'Sociedade Cultural Sino-Brasileira' realizou-se uma reunião de cunho social, promovida pela diretoria da entidade, com finalidade de inaugurar a referida sede e estreitar as relações entre seus associados. Entre as pessoas presentes, destacadas pelo comunicado em apreço, figura o nome de Maria Prestes Maia.22

Em vários outros movimentos e manifestações, Maria Prestes Maia foi agente, com destaque para a luta democrática e nacionalista, particularmente na "Frente Parlamentar Nacionalista". Esta organização suprapartidária foi criada em 1956, operou no Congresso Nacional, funcionava como um grupo de pressão que condenava o imperialismo, as ações do capital estrangeiro, reivindicando a regulamentação da remessa de lucros para o exterior, o controle estatal sobre a exploração dos recursos naturais básicos, além de assumir algumas reformas de base propostas, como a reforma agrária.

A Frente Nacionalista possibilitou uma troca dinâmica entre o poder legislativo e a

\section{e 15770.}

21 O Jornal “Diário Popular", em sua edição de 13/03/1965, publica relação dos envolvidos no Inquérito da "União Brasil-URSS" entre eles, a epigrafada. - Dossiê DEOPS/ AESP, n. 52-Z-0-14224, doc. 30-C-21-240.

22 Dossiê DEOPS/AESP, n. 52-Z-0-14224, doc. 50-Z-91576. O Jornal "Folha da Manhã", em sua edição de 25/05/1965, publicou o nome da epigrafada, entre outros elementos que faziam parte da Sociedade Cultural Sino-Brasileira, acusados de atividades subversivas. 
sociedade civil; seus membros se colocavam como porta-vozes de movimentos sociais e reivindicações populares (Ligas Camponesas, movimentos contra a carestia, União Nacional dos Estudantes, Comunidades Eclesiásticas de Base), em um momento de euforia participativa, com várias manifestações coletivas de cidadania e ações movidas por ideias de renovação (NEVES, s/d).

Segundo o Dossiê DEOPS, Maria Prestes Maia, no dia 20/09/1958:

Esteve no palanque armado no Largo de Pinheiros, quando, ali se realizou um comício comunista, promovido pela chamada 'Frente Nacionalista' em favor das entidades da coligação P.S.P. - P.T.B - P.R.T.

Em 1962, compôs a mesa diretora da Convenção Popular por uma Política Nacionalista e Democrática, ladeada por sujeitos políticos da esquerda, como pode ser observado:

Em 23/7/62 realizou-se no cine Paramount a 1. Convenção Popular por uma Política Nacionalista e Democrática, sendo mesa diretora ficado assim constituída: Luciano Lepera, Cid Franco, Maria de Lourdes Prestes Maia, Francisco Julião e outros. ${ }^{23}$

Ela apoiou vários movimentos grevistas, solidarizou-se com os trabalhadores e suas famílias, em várias ocasiões, quando da greve da Força Pública (fevereiro/1961), da greve na Indústria Brasileira de Refratários (outubro/1961), no Sindicato dos Metalúrgicos (junho/1962) e junto aos trabalhadores agrícolas

Em 13/11/61, foi realizada a 1 Conferência Estadual dos Lavradores e Trabalhadores Agrícolas, como preparatória do I Congresso Nacional dos Lavradores Trabalhadores Agrícolas, a realizarse em Belo Horizonte, nos dias 17, 18 e 19 corrente. $O$ ato contou com a presença de 500 pessoas muito dos quais, elementos comunistas, tendo tomada à mesa, a Sra. Maria de Lourdes Prestes Maia. ${ }^{24}$

23 Dossiê DEOPS/AESP, n. 52-Z-0-14224, doc. 30-C-1-15137. 24 Dossiê DEOPS/AESP, n. 52-Z-0-14224, doc. 30-J-57-473.
Com a morte de Prestes Maia, em abril de 1965, diminuiu sua presença pública, mas não sua ação política. Em 10 de julho de 1969, em um momento altamente repressivo, no contexto de ação do AI5, o DEOPS revelou, em declaração bombástica:

Acabamos de saber e identificar quem é o 'braço direito' dos comunistas, nesta capital, no setor financeiro, qual tem conseguido fundos elevados para a caixa do PCB sendo pesada perfeitamente integrada vida dos comunistas brasileiros.

Trata-se, simplesmente, de 'MARIA PORTUGUE$\mathrm{SA}^{\prime}$, mulher já algo madura na idade, mas tipo inteligente e insinuante, bem vistoso ainda, e, nada mais ou menos, que é a 'amante' direta do ex-prefeito Prestes Maia. A muito tempo que, não só se aproveitando das suas intimidades com o ilustre engenheiro, vem servindo de ponto entre burgueses e proletários, num serviço de infiltração da velha técnica com notáveis resultados, estando sempre ao par de planos e projetos da plutocracia política.

A demais, por intermédio das relações pessoais do ex-prefeito, ficou conhecida de muita gente importante, do comércio e da indústria, aos quais visita constantemente, e pede auxílios para a campanha do Partido Comunista, apegando-se as circunstâncias de que política a ser seguida é democrática-progressista, e muito distanciada, portanto, do combatido comunismo. 'O seu nome é MARIA DE LOURDES CABRAL'. ${ }^{25}$

Entre as várias lutas democráticas em que esteve envolvida, D. Maria, como portuguesa, atuou constantemente na causa antissalazarista. Ela mantinha relações com os conterrâneos opositores ao regime salazarista, em São Paulo, tanto os articulados em torno do Centro Republicano Português de São Paulo (reaberto em 1958), como os organizados em torno do Jornal Portugal Democrático, e vários de seus membros frequentavam sua casa e gozavam de sua amizade.

Certa feita, de passagem por Portugal, quis

25 Dossiê DEOPS/AESP, n. 52-Z-0-14224, doc. $50 Z 98812$. 
visitar a irmã e foi proibida de desembarcar pelo governo, como antissalazarista conhecida, e só obteve a autorização depois da interferência do Embaixador do Brasil.

Nesta frente, em 24/1/1960, esteve presente e discursou na:

Na Primeira Conferencia Sul-Americana Pro-Anistia para os Presos e Exilados Políticos de Espanha e Portugal, nos dias 23 e 24 . Na ocasião, recomendou a leitura de vários escritores portugueses, que narram as atrocidades cometidas nas prisões salazaristas. Solicitou que fossem enviados pedidos aos governos de Franco e Salazar, e também a ONU e a UNESCO, para a cessação desse estado de coisas. ${ }^{26}$

Manteve-se articulada a esta questão política, participando do ato público realizado em 27/7/62:

No Cine Paramount realizou-se o anunciado ato público de solidariedade aos trabalhadores e aos povos de Espanha e Portugal, no qual tomaram parte diversos deputados, entre os quais, Paulo de Tarso, João Lousada, Jethero Faria Cardoso, Luiz Carlos Prestes (líder vermelho), Cid Franco, Da. Maria Prestes Maia e outros elementos comunistas. ${ }^{27}$

Sua influência manteve-se, com a presença percebida e registrada no Movimento pela Anistia (anos 1970) e nas manifestações pelas Diretas Já (1980). Lideranças políticas buscavam o seu apoio, em diferentes momentos e ocasiões, com destaque para nomes como Ulisses Guimarães, Fernando Henrique Cardoso, Orestes Quércia e Ermínio de Moraes.

\section{Considerações finais}

Após a sua morte, em 25 de abril de 1988 (com 86 anos), prestaram-se várias homenagens a sua memória, sendo dado seu nome a uma Rua, na Vila Guilherme e a uma escola estadual, no Jardim Catarina.

26 Dossiê DEOPS/AESP, n. 52-Z-0-14224.

27 Dossiê DEOPS/AESP, n. 52-Z-0-14224.
A análise da trajetória de vida e lutas de Maria Prestes Maia tornou-se emblemática para a compreensão e o conhecimento da experiência histórica de uma imigrante portuguesa e sua participação nos circuitos culturais e políticos de São Paulo. Apesar das dificuldades enfrentadas, como o silêncio da personagem na bibliografia e na documentação, este desafio buscou dar visibilidade a suas várias experiências, como atriz, professora de teatro, e a suas ações no setor cultural, a na Federação das Mulheres do Brasil, na assistência social e nas várias frentes de luta política.

\section{Referências}

CAVAlCANTI, Pedro; DELION, Luciano. São Paulo e a juventude do Centro. São Paulo: Gripo, 2004.

Censo Estadual de 1934. Comissão Estadual de Recenseamento. Governo do Estado de São Paulo, São Paulo, 20 de setembro, 1934.

CORTI, Paola. Storia delle migrazioni internazionali. Roma: Editori Laterza, 2007.

FREITAS, Sonia Maria. Presença portuguesa em São Paulo. São Paulo: Imprensa Oficial, 2006.

HAAG, Carlos. Palco de razões e paixões. Pesquisa Fapesp, SP, n. 174, p. 87-89, 2010.

MATTOS, David José Lessa. 0 espetáculo da cultura paulista: teatro e TV em São Paulo, 1940-50. São Paulo: Códex, 2002.

MORSE, Richard. M. Formação histórica de São Paulo. São Paulo: Difel, 1970.

NEVES, Lucília Almeida. Frente Popular Nacionalista: utopia e cidadania. s/d. Disponivel em: <www. anpuh.org/arquivo/download?ID ARQUIVO=3743>. Acesso em: 21 ago. 2010.

PASCHOAL, Eliana dos Santos. Cenas de Arena de um teatro. Guarnieri e Vianinha 1958-1959. 1998. 150 f. Dissertação (Mestrado em História) - Programa de Pós-Graduação em História, Pontifícia Universidade Católica de São Paulo, PPG História da PUC/SP, São Paulo, 1998. 
PAVLOVA, Adriana. Maria Olenewa: a sacerdotisa do ritmo. Rio de Janeiro: FUNARTE, 2001.

PEREIRA, Miriam Halpern. A política portuguesa de emigração 1850-1930. Lisboa: Regra do Fogo, 1981.

SIMILI, Ivana Guilherme. Mulher e política: a trajetória da primeira-dama Darcy Vargas (1930-1945). São Paulo: Editora da UNESP, 2008.

\section{Depoimentos}

Adriana Prestes Maia Fernandes, acervo do Memorial dos Imigrantes de São Paulo, realizado em 5/09/2005.
Etty Fraser. Disponivel em: <aplauso.imprensaoficial.com.br/.../12.0.812.949.txt>. Acesso em: 17 ago. 2010.

Renato Borghi. Disponivel em: $\leq$ aplauso.imprensaoficial.com.br/edicoes/.../12.0.813.446.txt>. Acesso em: 17 ago. 2010.
Recebido em: 07.12.2017

Aprovado em: 08.02.2018

Maria Izilda Santos de Matos é Doutora em História pela USP, Livre-docente em História pela PUC/SP. Professora-titular da Pontificia Universidade Católica de São Paulo (PUC/SP). Pesquisadora 1A CNPq. e-mail: mismatos@pucsp.sp

Rua Monte Alegre 984, Perdizes - São Paulo/SP. Tel: (11) 55747744 